\title{
Assessing serum cytokine profiles in breast cancer patients receiving a HER2/neu vaccine using Luminex ${ }^{\circledR}$ technology
}

\author{
ZIA A. DEHQANZADA ${ }^{1,2}$, CATHERINE E. STORRER $^{1}$, MATTHEW T. HUEMAN $^{1,2}$, \\ REBECCA J. FOLEY ${ }^{1}$, KATIE A. HARRIS ${ }^{1}$, YUSUF H. JAMA ${ }^{1}$, CRAIG D. SHRIVER ${ }^{2}$, \\ SATHIBALAN PONNIAH ${ }^{1}$ and GEORGE E. PEOPLES ${ }^{1,2}$
}

\author{
${ }^{1}$ National Naval Medical Center, Henry M. Jackson Foundation, CBCP IRC Building 139, 8901 Wisconsin Avenue, \\ Bethesda, MD 20889; ${ }^{2}$ Department of Surgery, Walter Reed Army Medical Center, Clinical Breast \\ Care Project, 6900 Georgia Avenue NW, Washington, DC 20307, USA
}

Received April 18, 2006; Accepted May 29, 2006

\begin{abstract}
We used the Luminex assay to compare serum cytokine profiles of breast cancer patients (BCa) to healthy controls, node-positive (NP) patients to node-negative (NN), and pre- and post-vaccination serum of $\mathrm{BCa}$ vaccinated with a HER2/neu E75 peptide vaccine. Sera from 36 pre- and postvaccination $\mathrm{BCa},(12 \mathrm{NP}$ and $24 \mathrm{NN})$ and 13 healthy, female donors, were evaluated using Luminex technology. Levels of 22 cytokines consisting of interleukin (IL)- $1 \alpha,-1 \beta,-2,-4,-5,-6$, $-7,-8,-10,-12,-13,-15,-17$, IFN- $\gamma$, G-CSF, GM-CSF, TNF- $\alpha$, IP-10, MIP-1 $\alpha$, RANTES, eotaxin and monocyte chemotactic protein-1 (MCP-1) were assessed. Six of 22 cytokines showed significant differences between $\mathrm{BCa}$ and healthy controls. MCP-1, eotaxin, RANTES and GM-CSF levels were significantly elevated in $\mathrm{BCa}(\mathrm{P}<0.009)$ and IL- $1 \alpha$ and IL-4 levels were significantly decreased in $\mathrm{BCa}(\mathrm{P}<0.015)$. Cytokine levels were generally elevated in NN patients compared to NP patients with the exception of eotaxin and IL-13, which were increased in NP patients. Three cytokines, IL-6, MIP- $1 \alpha$ and G-CSF reached statistical significance $(\mathrm{P}<0.05)$. In 34 vaccinated $\mathrm{BCa}$, MCP-1, eotaxin and IL-13 were significantly elevated postvaccination with $\mathrm{MCP}-1$ demonstrating the most significant response (median, 145.8-217.0 pg/ml, P=0.003). Using a multiplex assay we found significant differences in cytokine levels in sera of BCa compared to healthy controls, in NN compared to NP patients, and in vaccinated patients. Our results support an extended analysis of serum cytokine profiles for the potential development of predictive panels in diagnosis, staging and monitoring cancer vaccine trials.
\end{abstract}

Correspondence to: Dr George E. Peoples, National Naval Medical Center, Henry M. Jackson Foundation, CBCP IRC Building 139, 8901 Wisconsin Avenue, Bethesda, MD 20889, USA

E-mail: george.peoples@amedd.army.mil

Key words: HER2/neu E75-peptide vaccine, Luminex ${ }^{\circledR}$ multiplex assay, serum cytokines

\section{Introduction}

Despite the wide clinical use of serum tumor markers like PSA, CEA and CA-125, the clinical utility for screening patients for tumor-related proteins in the setting of breast cancer has been limited. The ideal tumor marker for a screening test must be tumor-specific, easily measurable in accessible tissue (such as serum), and demonstrate near 100\% sensitivity and specificity in order to avoid false positive and negative results. Unfortunately, such a tumor marker does not exist for breast cancer. The lack of sensitivity and specificity of tumor markers in general, but especially those related to breast neoplasms, led to the 2001 recommendation of the American Society of Clinical Oncology to discourage the routine use of tumor markers in the context of breast cancer except in specific circumstances (1).

Advances in technology in the field of proteomics have shifted the focus from monitoring a single-tumor marker to assessing multiple serum proteins and the development of predictive protein patterns. Petricoin et al used serum protein patterns to develop predictive panels in diagnosing ovarian cancer at early stages (2). While the analysis in the study by Petricoin et al included a whole spectra of protein expression, mathematical modeling has shown that as few as seven to nine proteins could be used for generating predictive patterns from a given dataset (3). In these types of studies, the identity of the proteins is often irrelevant. Therefore if predictive patterns of unknown serum proteins exist, then one might question whether predictive patterns of known tumor-related serum proteins could also be present for the detection of cancer.

Cytokines are small polypeptides generally divided into pro- and anti-inflammatory subsets. The former is produced by type $1 \mathrm{~T}$-helper cells (Th1) and the latter produced by the type 2 T-helper cells (Th2). Another class of proteins called chemokines is a subset of the cytokine family that is responsible for chemotaxis of specific cells. Given that cytokines and chemokines are serum proteins that are often associated with the presence of tumor, a global approach on assessing multiple cytokine concentrations as a measure of the interaction between the immune system and the tumor may potentially yield new methods that are useful for the diagnosis and/or prognosis of 
cancer patients. The Luminex multiplex technology is a recent advance in protein profiling which has allowed for marked efficiency in analyzing small volumes of specimens for a large number of analytes in a significantly reduced amount of time. Multiplexing technology has been utilized for detection of multiple proteins to include enzymes, cytokines and other antigens (4-6). In addition, this technology can also be used for large-scale genetic analysis $(7,8)$.

We are currently conducting phase I/II studies investigating a HER2/neu immunogenic peptide (E75) with GM-CSF as a simple vaccine strategy for breast and prostate cancer. We are vaccinating immunocompetent patients with breast or prostate cancer who are disease-free after standard conventional therapies, but who are at high-risk for recurrence $(9,10)$ in order to determine if induced E75-specific immunity conveys clinical benefit by preventing recurrence. In this study, we test our hypothesis that serum cytokine analysis may be useful for diagnosis, staging, and/or determining response to therapy in the setting of breast cancer. Therefore, we have used Luminex technology to assess simultaneously the serum levels of 22 different cytokines in breast cancer patients before and after vaccination with the E75 + GM-CSF vaccine. We have compared the pre-vaccination serum cytokine profiles with those of normal healthy donors. We have also looked for differences in the cytokine levels based on stage of disease among the breast cancer patients. Finally, we have evaluated the differences in the serum cytokine profile after vaccination with the HER2/neu-derived vaccine in order to determine whether this type of analysis may be useful for monitoring vaccine trials as well as, more generally, for diagnosing and/or staging breast cancer patients.

\section{Materials and methods}

Patient characteristics and clinical protocols. The Department of Clinical Investigation, Walter Reed Army Medical Center, approved these clinical protocols. These clinical trials were conducted under an Investigational New Drug Application (IND\#9187) approved by the Food and Drug Administration. All patients had histologically-confirmed breast cancer that expressed HER2/neu by standard immunohistochemistry. All breast cancer patients had completed a standard course of surgery, chemotherapy and/or radiation therapy, as required, prior to enrollment. After screening for eligibility criteria and proper counseling and consenting, these patients were enrolled into the studies and were then HLA typed to determine their HLA-A2 status since E75 binds this specific HLA allele found in approximately $40-50 \%$ of the general population (11). HLA-A2 ${ }^{+}$patients were vaccinated while HLA-A2- patients were followed prospectively as matched controls for clinical recurrence. Prior to vaccination, patients were skin tested with a panel of recall antigens (Mantoux test $=$ mumps, tetanus, candida). Patients were considered immunocompetent if they reacted $(>5 \mathrm{~mm})$ to $\geq 2$ antigens.

Vaccine. The E75 peptide ( $>95 \%$ purity) was produced in good manufacturing practices grade by Multiple Peptide Systems (San Diego, CA). Sterility and general safety testing was carried out by the manufacturer. Lyophilized peptide was reconstituted in sterile saline at the following concentrations:
$100 \mu \mathrm{g}$ in $0.5 \mathrm{ml}, 500 \mu \mathrm{g}$ in $0.5 \mathrm{ml}$, and $1 \mathrm{mg}$ in $0.5 \mathrm{ml}$. The peptide was mixed with GM-CSF (Berlex, Seattle, WA) at $250 \mu \mathrm{g}$ in $0.5 \mathrm{ml}$, and the $1.0 \mathrm{ml}$ inoculation was split and given intradermally at two sites within $5 \mathrm{~cm}$ of each other. All inoculations were given in the same extremity.

$N P$ vaccination series. The study was performed as a two-stage safety trial. In the first stage, three patients were assigned to each dose/schedule group receiving six monthly inoculations: $100 \mu \mathrm{g}$ (100.6), $500 \mu \mathrm{g}$ (500.6) or $1000 \mu \mathrm{g}$ (1000.6) of E75 peptide + GM-CSF. A fourth group received $500 \mu \mathrm{g}$ of peptide + GM-CSF but only four inoculations (500.4), omitting the fourth and fifth vaccinations. In the second stage, four additional groups with six patients each were vaccinated as follows: 500.4, 500.6, 1000.6 and 1000.4. All of the NP vaccinated patients discussed in this manuscript belonged to the second stage of this trial and were a part of the 500.6 (3 patients), 500.4 (3 patients), 1000.6 (3 patients) and 1000.4 (3 patients) categories, all receiving $250 \mu \mathrm{g}$ of GM-CSF. The choice of the patients from the second stage of the trial was due to the implementation of a serum banking strategy that was activated only during the second stage of the trial.

NN vaccination series. NN patients have also undergone primary surgical and medical therapies and were considered to be without evidence of disease at the time of enrollment into the trial. The purpose of this ongoing trial is to determine the optimal dose of the immunoadjuvant, GM-CSF, and the optimal schedule of inoculations for the E75 + GM-CSF vaccine. Patients are vaccinated according to a dose and schedule escalation scheme (five groups with ten patients in each). The first group of ten patients in the trial was vaccinated with $500 \mu \mathrm{g}$ of E75 peptide and $125 \mu \mathrm{g}$ of GM-CSF under schedule 1 ( 0,1 and 5 months for a total of three doses), and the second group was vaccinated with the same dosing but under schedule $2(0,1,2$ and 5 months for a total of four doses). The third group of ten patients is receiving $500 \mu \mathrm{g}$ of the E75 peptide vaccine in addition to $250 \mu \mathrm{g}$ of GM-CSF under schedule 2 . The two remaining groups of the five total groups are to be vaccinated with escalating doses of GM-CSF and E75 peptide under either one of the two schedules. All of the NN patients discussed in this manuscript were from the first three groups.

Peripheral blood collection and preparation of serum. Peripheral blood was drawn from patients prior to receiving each inoculation and at one and six months after completing the series for the isolation of cells used in immunological monitoring assays of the clinical trials (12). For the preparation of serum samples $10 \mathrm{ml}$ of peripheral blood was drawn into a Vacutainer Gel and Clot Activator tube (Becton-Dickinson, Franklin Lakes, NJ), and centrifuged in order to separate out the serum. The serum was aliquoted into NUNC-cryovial tubes and placed in a $-84^{\circ} \mathrm{C}$ freezer. The pre- and post-vaccination blood samples used for these studies were obtained prior to the start of the vaccine series and one month after the second vaccination, respectively. A preliminary study in six patients ( $3 \mathrm{NP}$ and $3 \mathrm{NN}$ ) monitoring the levels of cytokines monthly after initiation of the vaccine series showed that the maximal response usually occurred after two or three doses of vaccine 
Table I. Median serum levels of selected cytokines in 13 normal, healthy controls and 22 breast cancer patients.

\begin{tabular}{|c|c|c|c|c|c|c|c|}
\hline \multirow[b]{2}{*}{ Cytokines } & \multicolumn{3}{|c|}{ Control (pg/ml) $(\mathrm{n}=13)$} & \multicolumn{3}{|c|}{ Cancer (pg/ml) (n=22) } & \multirow[b]{2}{*}{$\mathrm{P}$-value } \\
\hline & Median & Min & Max & Median & Min & Max & \\
\hline IL- $1 \alpha$ & 11.18 & 5.50 & 17.04 & 8.800 & 7.01 & 24.47 & 0.007 \\
\hline IL-1ß & 2.64 & 2.41 & 2.89 & 2.690 & 2.53 & 3.49 & 0.18 \\
\hline IL-2 & 1.47 & 1.04 & 2.61 & 1.610 & 1.15 & 2.45 & 0.35 \\
\hline IL-4 & 11.05 & 6.68 & 15.38 & 7.200 & 5.64 & 157.74 & 0.015 \\
\hline IL-6 & 0.00 & 0.00 & 89.50 & 0.000 & 0.00 & 0.00 & NS \\
\hline IL-8 & 2.57 & 0.80 & 6.63 & 2.690 & 1.36 & 26.34 & 0.25 \\
\hline IL-10 & 1.66 & 0.24 & 2.67 & 1.550 & 0.67 & 6.30 & 0.64 \\
\hline IL-12 & 3.42 & 3.06 & 3.73 & 3.500 & 3.28 & 4.08 & 0.25 \\
\hline IL-13 & 12.33 & 7.81 & 19.22 & 13.420 & 10.67 & 27.01 & 0.29 \\
\hline IL-15 & 0.12 & 0.00 & 1.81 & 0.490 & 0.00 & 5.31 & 0.24 \\
\hline IL-17 & 0.00 & 0.00 & 3.10 & 0.135 & 0.00 & 2.22 & 0.41 \\
\hline IP-10 & 58.00 & 9.00 & 287.00 & 64.750 & 28.00 & 185.00 & 0.20 \\
\hline MCP-1 & 50.28 & 0.00 & 73.84 & 131.58 & 21.55 & 220.93 & 0.001 \\
\hline MIP- $1 \alpha$ & 25.64 & 15.51 & 58.56 & 26.860 & 19.76 & 45.45 & 0.20 \\
\hline RANTES ${ }^{a}$ & 13361 & 5534.50 & 20569.00 & 22343.500 & 7481.00 & 24703.00 & 0.0001 \\
\hline Eotaxin & 18.28 & 16.25 & 26.79 & 30.220 & 16.61 & 88.30 & 0.001 \\
\hline G-CSF & 0.00 & 0.00 & 0.00 & 0.000 & 0.00 & 0.00 & NS \\
\hline GM-CSF & 2.56 & 1.86 & 2.81 & 2.950 & 2.26 & 3.99 & 0.009 \\
\hline IFN- $\gamma$ & 5.00 & 4.42 & 5.66 & 5.330 & 4.78 & 6.26 & 0.09 \\
\hline
\end{tabular}

aRANTES is measured in MFI. IL, interleukin; IFN- $\gamma$, interferon- $\gamma$; IP-10, IFN- $\gamma$ inducible protein-10; MIP-1 $\alpha$, macrophage inflammatory protein-1 $\alpha$; RANTES, regulated on activation normal T cell expressed and secreted; GM-CSF, granulocyte-macrophage colony stimulating factor; G-CSF, granulocyte-colony stimulating factor; MCP-1, monocyte chemotactic protein-1.

for the majority of the cytokines reported. Thirteen commercially available serum samples from females were used as healthy controls in our study (Gemini Bio-Products, Woodland, CA). The age range of these controls was 18-51 years. Bearing in mind that variations could potentially arise from differences in collection and processing methods, the procedures for collection, preparation, freezing and thawing of all the serum samples used in this study were performed in a highly consistent manner including the collection and handling of the commercial samples. None of the serum samples had been previously thawed prior to thawing for the Luminex assay.

Serum cytokine analysis by Luminex technology. We used the Luminex 100 system (Luminex Corp., Austin, TX) in multiple experiments to evaluate the sera from a total of 36 breast cancer patients ( $24 \mathrm{NN}$ and $12 \mathrm{NP}$ ) who were deemed without evidence of disease following standard therapies. Levels of 22 cytokines consisting of interleukin (IL)- $1 \alpha,-1 \beta,-2,-4,-5,-6$, $-7,-8,-10,-12,-13,-15,-17$, IFN- $\gamma$, G-CSF, GM-CSF, TNF- $\alpha$, IP-10, MIP-1 $\alpha$, RANTES, eotaxin and MCP-1 were assessed. The assays were repeated and our data was replicated. We used the Lincoplex Kit (Linco Research, St. Charles, MO). Briefly, $25 \mu 1$ of diluent and $25 \mu 1$ of serum were added to each well. Mixed micro-beads $(25 \mu 1)$ were added. The plate was incubated and agitated for $1 \mathrm{~h}$, washed and re-incubated with $25 \mu 1$ of detection antibody for $30 \mathrm{~min}$. The plate was washed again and incubated with $25 \mu 1$ of Streptavidin-Phycoerythrin for $30 \mathrm{~min}$. The plate was then washed twice and the beads were re-suspended in the plate with $100 \mu 1$ sheath fluid and analyzed using the Luminex 100 system. The readout for the concentration of each cytokine was detected as mean fluorescence intensity (MFI) by the instrument. These values were subsequently converted to $\mathrm{pg} / \mathrm{ml}$ of cytokine based upon the MFI values from a set of standards that were run simultaneously in the assay. The cytokine RANTES had a higher MFI than the maximum standard dilution tested in its concentration curve. The assay could not give an absolute $\mathrm{pg} / \mathrm{ml}$ value for this cytokine given that the MFI exceeded the standard dilution. We used a value higher than the most concentrated standard dilution as an absolute value for RANTES. Usage of this absolute value versus the MFI for RANTES did not alter the analysis of the results.

Statistics. Summary statistics were obtained using established methods. Associations between non-parametric categorical variables were evaluated using the Wilcoxin sign rank test for the related data and the Wilcoxin rank sum test for unrelated data. A value of $<0.05$ was considered significant.

\section{Results}

Serum cytokine levels in breast cancer patients versus healthy individuals. For the comparison of serum cytokine levels between cancer patients and healthy individuals we tested sera from 13 healthy females and 22 breast cancer patients. The average age of the breast cancer patients was 59.7 years. 


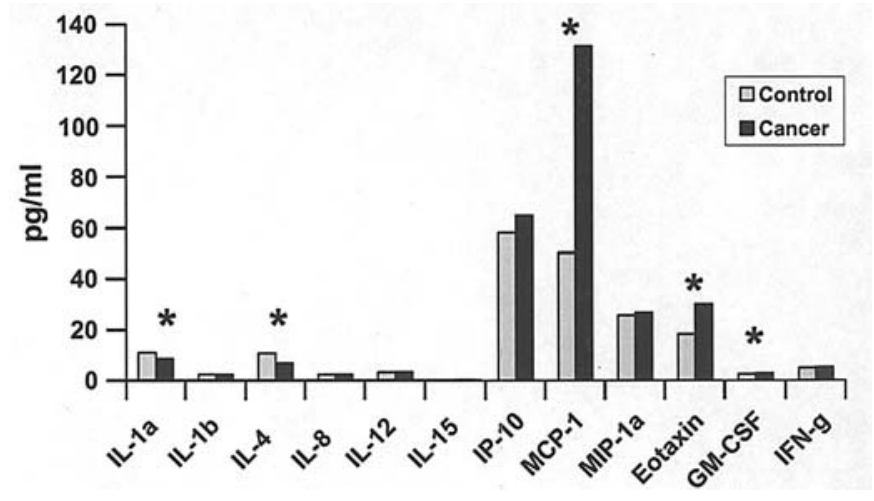

Figure 1. Selected serum cytokine levels in breast cancer versus control patients. Serum was collected from 22 breast cancer patients and 13 normal, healthy controls and was analyzed for levels of 22 cytokines using Luminex technology. Results are expressed as median values in $\mathrm{pg} / \mathrm{ml}$. *Statistically different findings $(\mathrm{P}<0.05)$. RANTES is measured in MFI.

Approximately $52 \%$ of the patients had received chemotherapy with an average of 28.7 months elapsed from the end of chemotherapy to enrollment into our protocol. Four cytokines (RANTES, GM-CSF, eotaxin and MCP-1) had statistically significant increases in the sera of cancer patients (Table I). MCP-1 median (range) serum level was markedly elevated in cancer patients versus controls [131.6 pg/ml (21.6-220.9 pg/ $\mathrm{ml})$ versus $50.3 \mathrm{pg} / \mathrm{ml}(0-73.8 \mathrm{pg} / \mathrm{ml})$, respectively] $(\mathrm{P}=0.001)$ (Fig. 1). Seven cytokines (IL-2, IL-8, IL-15, IL-13, IP-10,
MIP- $1 \alpha$ and IFN- $\gamma$ ) had an identifiable increase in cancer patients as measured by serum median levels; however, they did not reach statistical significance. Three cytokines (IL-1ß, IL-12 and IL-17) did not show any marked changes between cancer and control groups. Four of the 22 cytokines (IL-5, IL-7, G-CSF and TNF- $\alpha$ ) had no reactivity. IL-6 had minimal values for only two NN patients. Interleukins $1 \alpha, 4$ and 10 demonstrated a decrease in serum levels of cancer patients while the former two reached statistical significance (Table I). These data suggest a generalized pro-inflammatory state in the cancer patients compared to normal healthy donors that may be suggestive evidence of an ongoing or previous endogenous anticancer immune response.

Serum cytokine levels in NP versus NN breast cancer patients. Serum samples from a total of 36 patients (12 NP and $24 \mathrm{NN}$ ) were used for the comparison of cytokine levels in NP versus NN breast cancer patients. The average age for the NP and NN cohorts was 54 and 53 years, respectively. Approximately $44 \%$ of NN patients and $92 \%$ of the NP patients had received chemotherapy $(\mathrm{P}=0.02)$ and the average duration from end of chemotherapy to enrollment was 25.2 and 14.2 months, respectively $(\mathrm{P}=0.33)$. Overall, compared to the NP patients, the NN patients had increased levels of most cytokines except eotaxin and IL-13, which were increased in NP patients (Table II). Seven cytokines (RANTES, MCP-1, IL-1 $\alpha$, IL-6, IP-10, MIP- $1 \alpha$ and G-CSF) were substantially increased in the NN cohort (Fig. 2). The NN serum levels of IL-6, MIP-1 $\alpha$

Table II. Median serum levels of selected cytokines in 36 node-positive (NP) and node-negative (NN) breast cancer patients.

\begin{tabular}{|c|c|c|c|c|c|c|c|}
\hline \multirow[b]{2}{*}{ Cytokines } & \multicolumn{3}{|c|}{$\mathrm{NP}(\mathrm{pg} / \mathrm{ml})(\mathrm{n}=12)$} & \multicolumn{3}{|c|}{$\mathrm{NN}(\mathrm{pg} / \mathrm{ml})(\mathrm{n}=24)$} & \multirow[b]{2}{*}{ P-value } \\
\hline & Median & Min & $\operatorname{Max}$ & Median & Min & Max & \\
\hline IL-1 $\alpha$ & 0.0 & 0.00 & 33.90 & 7.6 & 0.0 & 117.9 & 0.224 \\
\hline IL-1ß & 3.9 & 3.80 & 4.30 & 4.1 & 2.6 & 6.0 & 0.084 \\
\hline IL-2 & 0.0 & 0.00 & 0.00 & 0.0 & 0.0 & 2.1 & 0.70 \\
\hline IL-4 & 0.0 & 0.00 & 57.90 & 0.0 & 0.0 & 1679.2 & 0.27 \\
\hline IL-6 & 9.4 & 0.00 & 20.20 & 14.7 & 0.0 & 525.9 & 0.04 \\
\hline IL-8 & 0.0 & 0.00 & 54.40 & 0.0 & 0.0 & 437.7 & 0.19 \\
\hline IL-10 & 0.0 & 0.00 & 0.00 & 0.0 & 0.0 & 3.8 & 0.56 \\
\hline IL-12 & 0.0 & 0.00 & 0.00 & 0.0 & 0.0 & 3.9 & 0.11 \\
\hline IL-13 & 19.2 & 2.90 & 40.70 & 10.5 & 0.0 & 51.0 & 0.11 \\
\hline IL-15 & 0.0 & 0.00 & 0.00 & 0.0 & 0.0 & 9.7 & 0.56 \\
\hline IL-17 & 1.6 & 1.36 & 2.70 & 1.6 & 0.1 & 3.6 & 0.46 \\
\hline IP-10 & 56.5 & 36.70 & 180.00 & 110.4 & 11.6 & 492.2 & 0.15 \\
\hline MCP-1 & 116.1 & 40.80 & 244.60 & 187.4 & 28.8 & 617.3 & 0.10 \\
\hline MIP-1 $\alpha$ & 2.4 & 0.00 & 294.20 & 6.2 & 0.8 & 34.0 & 0.02 \\
\hline RANTES $^{\mathrm{a}}$ & 20011.0 & 18018.00 & 23159.00 & 22535.0 & 7481.0 & 24703.0 & 0.41 \\
\hline Eotaxin & 48.3 & 11.30 & 86.30 & 39.9 & 0.0 & 374.5 & 0.61 \\
\hline G-CSF & 13.1 & 0.00 & 33.70 & 23.4 & 0.0 & 63.5 & 0.02 \\
\hline GM-CSF & 0.0 & 0.00 & 1.44 & 0.0 & 0.0 & 10.2 & 0.25 \\
\hline IFN- $\gamma$ & 0.0 & 0.00 & 0.00 & 0.0 & 0.0 & 247.6 & 0.09 \\
\hline
\end{tabular}

aRANTES is measured in MFI. IL, interleukin; IFN- $\gamma$, interferon; IP-10, IFN- $\gamma$ inducible protein-10; MIP-1 $\alpha$, macrophage inflammatory protein-1 $\alpha$; RANTES, regulated on activation normal T cell expressed and secreted; GM-CSF, granulocyte macrophage-colony stimulating factor; G-CSF, granulocyte-colony stimulating factor; MCP-1, monocyte chemotactic protein-1. 


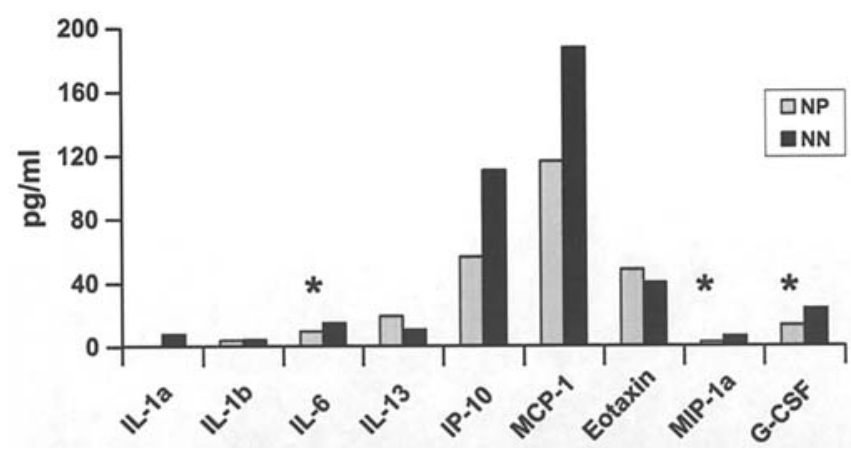

Figure 2. Selected serum cytokine levels in NP versus NN breast cancer patients. Serum was collected from $12 \mathrm{NP}$ and $24 \mathrm{NN}$ breast cancer patients and was analyzed for levels of 22 cytokines using Luminex technology. Results are expressed as median values in $\mathrm{pg} / \mathrm{ml}$. "Statistically different findings $(\mathrm{P}<0.05)$. RANTES is measured in MFI.

and G-CSF compared to NP cohort were 14.7 versus $9.4 \mathrm{pg} / \mathrm{ml}$, 6.2 versus $2.4 \mathrm{pg} / \mathrm{ml}$, and 23.4 versus $13.1 \mathrm{pg} / \mathrm{ml}$, respectively $(\mathrm{P}<0.05)$. Two cytokines, IL-1ß and IL-17, did not demonstrate any changes between NN and NP patients. The levels of eight cytokines, IL-2, $-4,-8,-10,-12,-15$, GM-CSF and IFN- $\gamma$, in the serum samples of both NP and NN patients were found to be below the limits of detection of this assay (Table II). In general, these data suggest a more pronounced pro-inflammatory state in the NN patients compared to the NP.
Cytokine levels in pre- and post-vaccination sera of breast cancer patients. We are conducting a clinical trial of a HER2/ neu peptide-based vaccine in NN and NP breast cancer patients. Serum samples from 34 patients were available for the comparison of cytokine levels prior to and after vaccination in order to investigate changes in serum cytokine patterns that may be associated with our administration of the HER2/neu E75-peptide vaccine. Blood drawn immediately prior to the first vaccination was compared to the blood drawn after two inoculations. Of the 22 cytokines screened, seven were increased post-vaccination (Table III). These cytokines were IL-1 $\alpha$, IL-6, IP-10, G-CSF, IL-13, eotaxin and MCP-1 (Fig. 3A). A statistically significant increase post-vaccination in cancer patients compared to pre-vaccination time-points were observed in IL-13 (19.2 versus $15.0 \mathrm{pg} / \mathrm{ml}$ ), MCP-1 (217.0 versus $145.8 \mathrm{pg} / \mathrm{ml}$ ) and eotaxin (55.8 versus $45.6 \mathrm{pg} /$ $\mathrm{ml})(\mathrm{P}<0.05)$, respectively. The serum level of IL- $1 \alpha$ approached statistical significance. One cytokine serum level, MIP-1 $\alpha$, was decreased post-vaccination (Table III). The remainder of the cytokines did not demonstrate significant changes. These data suggest that the vaccine may be inducing a more pro-inflammatory state.

Cytokine levels in pre- and post-vaccination sera of $N N$ versus NP breast cancer patients. Serum samples from a total of 10 $\mathrm{NP}$ and $24 \mathrm{NN}$ patients were available for analysis of cytokines at the pre- and post-vaccination time-points. In the NN group,

Table III. Median pre- and post-vaccination serum levels of selected cytokines in 34 breast cancer patients.

\begin{tabular}{|c|c|c|c|c|c|c|c|}
\hline \multirow[b]{2}{*}{ Cytokines } & \multicolumn{3}{|c|}{ Pre-vaccination $(\mathrm{pg} / \mathrm{ml})(\mathrm{n}=34)$} & \multicolumn{3}{|c|}{ Post-vaccination $(\mathrm{pg} / \mathrm{ml})(\mathrm{n}=34)$} & \multirow[b]{2}{*}{ P-value } \\
\hline & Median & Min & Max & Median & Min & Max & \\
\hline IL- $1 \alpha$ & 2.3 & 0.0 & 117.9 & 11.7 & 0.0 & 164.7 & 0.11 \\
\hline IL-1ß & 4.0 & 2.6 & 6.0 & 4.1 & 2.7 & 7.8 & 0.76 \\
\hline IL-2 & 0.0 & 0.0 & 2.1 & 0.0 & 0.0 & 2.1 & 0.18 \\
\hline IL-4 & 0.0 & 0.0 & 1679.2 & 0.0 & 0.0 & 1174.4 & 0.06 \\
\hline IL-6 & 14.7 & 0.0 & 525.9 & 18.8 & 0.0 & 480.4 & 0.42 \\
\hline IL-8 & 0.0 & 0.0 & 437.7 & 0.0 & 0.0 & 431.2 & 0.60 \\
\hline IL-10 & 0.0 & 0.0 & 3.8 & 0.0 & 0.0 & 5.4 & 0.47 \\
\hline IL-12 & 0.0 & 0.0 & 3.9 & 0.0 & 0.0 & 3.6 & 0.54 \\
\hline IL-13 & 15.0 & 0.0 & 51.0 & 19.2 & 0.0 & 74.9 & 0.04 \\
\hline IL-15 & 0.0 & 0.0 & 9.7 & 0.0 & 0.0 & 3.6 & NS \\
\hline IL-17 & 1.6 & 0.1 & 3.6 & 1.6 & 0.4 & 4.4 & 0.18 \\
\hline IP-10 & 95.5 & 11.6 & 492.2 & 97.5 & 14.1 & 908.1 & 0.59 \\
\hline MCP-1 & 145.8 & 28.8 & 617.3 & 217.0 & 35.9 & 579.8 & 0.003 \\
\hline MIP-1 $1 \alpha$ & 5.8 & 0.0 & 294.2 & 3.9 & 0.0 & 135.4 & 0.72 \\
\hline RANTES $^{a}$ & 22552.0 & 7481.0 & 24703.0 & 22538.0 & 3715.0 & 24353.0 & 0.84 \\
\hline Eotaxin & 45.6 & 0.0 & 374.5 & 55.8 & 6.9 & 457.0 & 0.01 \\
\hline G-CSF & 20.6 & 0.0 & 63.5 & 26.1 & 0.0 & 62.8 & 0.28 \\
\hline GM-CSF & 0.0 & 0.0 & 10.2 & 0.0 & 0.0 & 14.7 & 0.71 \\
\hline $\mathrm{IFN}-\gamma$ & 0.0 & 0.0 & 247.6 & 0.0 & 0.0 & 5.4 & 0.23 \\
\hline
\end{tabular}

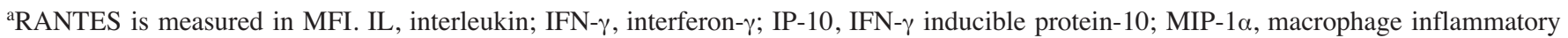
protein-1 $\alpha$; RANTES, regulated on activation normal T cell expressed and secreted; GM-CSF, granulocyte macrophage-colony stimulating factor; G-CSF, granulocyte-colony stimulating factor; MCP-1, monocyte chemotactic protein-1. 
A

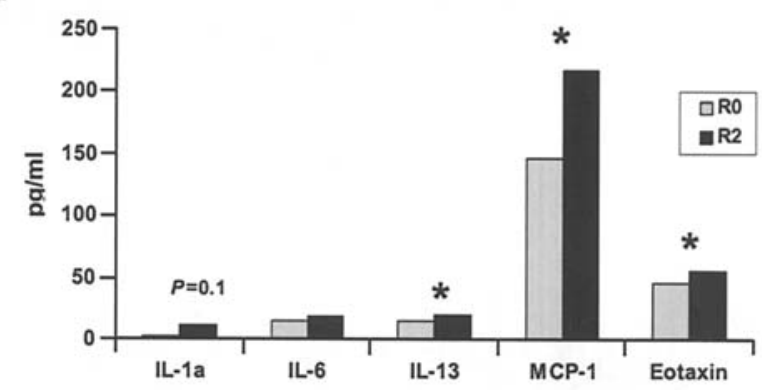

B

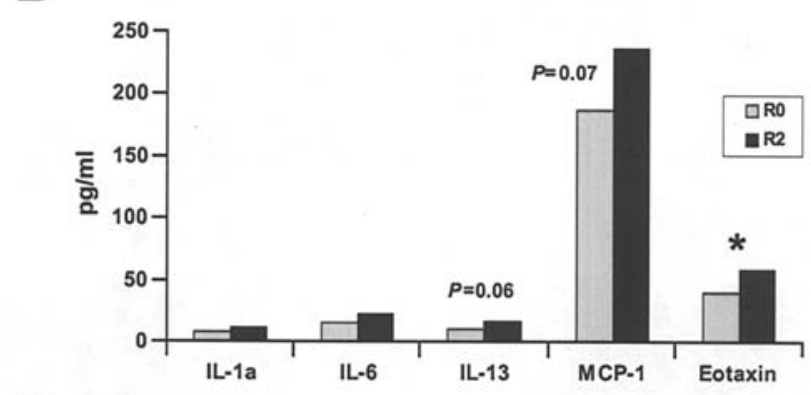

C

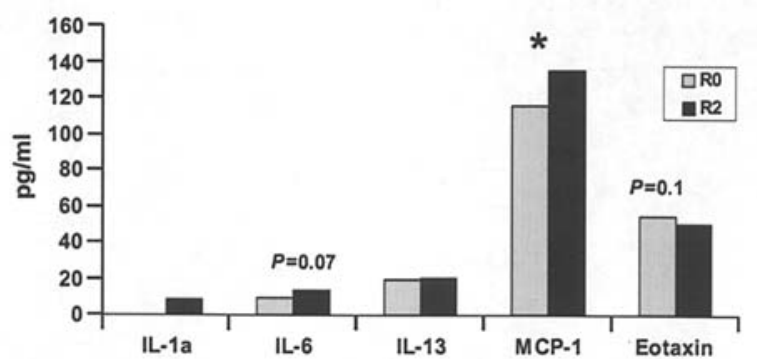

Figure 3. Selected serum cytokine levels pre- and post-vaccination in 34 breast cancer patients analyzed for levels of 22 cytokines at two separate time-points in the vaccination schedule. (A) All patients, (B) NN patients, and (C) NP patients. Results are expressed in $\mathrm{pg} / \mathrm{ml}$ and median values, asterisks and $\mathrm{P}$-values indicate statistically significant findings. R0, prevaccination (immediately prior to receiving vaccine); R2, post-vaccination (a month after receiving the 2 nd dose of vaccine).

the serum eotaxin level increased post-vaccination from 39.9 to $58.4 \mathrm{pg} / \mathrm{ml}(\mathrm{P}=0.03)$, while in the NP cohort the postvaccination level decreased from $54.7 \mathrm{pg} / \mathrm{ml}$ at pre-vaccination time-point to $50.2 \mathrm{pg} / \mathrm{ml}(\mathrm{P}=0.14)$ (Fig. 3B and C). Postvaccination serum MCP-1 level was increased in both NN and NP subsets. However, NP patients demonstrated a statistically significant increase in sera MCP-1 level between pre- to postvaccination ( 116.1 versus $134.9 \mathrm{pg} / \mathrm{ml}, \mathrm{P}=0.01)$, respectively. The latter finding may be significant since the NP patients were found to be deficient of this apparently important proinflammatory cytokine compared to the $\mathrm{NN}$ patient group.

\section{Discussion}

In this study, we have shown that breast cancer patients without evidence of disease following standard therapies have elevated levels of pro-inflammatory mediators including MCP-1 and eotaxin in their serum when compared to healthy individuals. Within the group of breast cancer patients, NN patients demonstrated higher levels of pro-inflammatory mediators compared to NP patients with the exception of eotaxin and IL-13, which were increased in NP patients. Analysis of post-vaccination sera from breast cancer patients receiving a HER2/neu E75-peptide vaccine showed that the pro-inflammatory cytokines eotaxin and MCP-1 were increased in response to the vaccination. Collectively, these overall differences in serum cytokine profiles may be indicative of an endogenous immune response to the cancer state. More importantly, the differences may be exploited to develop predictive serum cytokine patterns or included with other serum tumor markers for the evaluation of more accurate serum tests that can be utilized in the screening, diagnosis and staging of breast cancer patients.

One concept of cancer immunity in the field of immunotherapy is the assumption that tumors can invoke a generalized anergic state in the host $(13,14)$. Halak et al demonstrated that murine bladder tumors (MB-49) induce stromal cells to produce IL-10, evoking a Th2-type immunity and failure of the immune system to prime for the cancer-specific antigen (HY). Performing the same experiment in IL-10 knockout mice allowed for a Th1-type immunity and adequate priming of HY-specific T cells (13). Others have reported that tumor escape from the immune system is not due to global anergy, but rather is due to a lack of quantitative immunologic response to the tumor (15). In our study, we observed a decreased immune response as measured by levels of serum pro-inflammatory cytokine in the patients exposed to larger tumor burdens. The observation of increased serum levels of Th1-type cytokines such as MCP-1 and IL- $1 \alpha$ in the NN versus the NP cohort while demonstrating increased IL-13 levels in NP versus NN patients further supports this statement. Since the majority of our cancer population consisted of NN patients, we observed an increased pro-inflammatory cytokine profile (RANTES, eotaxin and $\mathrm{MCP}-1$ ) in the cancer group as compared to controls. This suggests the possibility that the vigorous immune response observed in our NN patients may have produced a protective effect and a survival advantage in these individuals.

The majority of the cytokine analyses, whether in the tumor microenvironment or serum, have been performed using enzyme linked immuno-sorbent assay (ELISA) technology. The sensitivity of ELISA is appreciably enhanced by the development of dissociation-enhanced lanthanide fluoroimmunoassay (DELFIA) (6). Even though these technologies have demonstrated good sensitivity and specificities, their use is accompanied with certain shortcomings. First, they are capable of measuring only one protein at a time. This limitation would translate into utilization of a large volume of specimen while attempting evaluation of multiple proteins. Furthermore, ELISA assays are time consuming and labor intensive. In contrast, multiplexing platforms allow for using as little as $25 \mu \mathrm{l}$ of serum for analyzing as many as 100 cytokines or other analytes, and the assay can be completed in a day.

To our knowledge, no studies attempting a thorough profiling of multiple Th1 and Th2 serum cytokines in the context of breast cancer, especially in NN versus NP patients, have been published. However, there are reports of isolated serum cytokine analysis, largely limited to one or two cytokines, in the context of breast cancer as well as other malignancies. In their study of MCP-1 serum levels in breast cancer 
patients, Lebrecht et al did not demonstrate any significant difference in serum levels of invasive, DCIS, benign disease or normal patients but found a correlation between MCP-1 levels and tumor stage as well lymph node involvement (16). In contrast, a retrospective study evaluating the serum MCP-1 levels in patients with primary ovarian cancer, recurrent ovarian cancer, benign ovarian disease, and healthy women demonstrated significant elevated serum levels of MCP-1 in patients with malignant disease compared with healthy controls (17). MCP-1 and eotaxin are both members of the C-C chemokine family and function in chemotaxis of monocytes and eosinophils, respectively (18-20). The cytokine MCP-1 has been extensively studied in the context of the tumor microenvironment and is implicated in tumorigenesis, angiogenesis and the metastatic process $(21,22)$. Eotaxin, however, has been studied in allergic pathways and mammary ductal morphogenesis (23). The observation that MCP-1 and eotaxin were consistently elevated in sera of cancer population versus controls as well as post-vaccination time-points compared to pre-vaccinated time-points is indeed intriguing and may warrant further evaluation of their role in disease in breast cancer patients.

Proteomics assays have been used successfully in screening and correctly diagnosing patients with early ovarian cancer $(2,3)$. Our findings in this study represent an initial investigation of the utility of multiplex technology for a combined application of screening for cytokine immuno-profiles and vaccineresponses in breast cancer patients participating in a cancer peptide vaccine clinical trial. We acknowledge that albeit intriguing and promising, these are preliminary results that have some limitations with room for improvement. For example, there was a lack of uniformity in vaccine dosing to our patient population. The pre-vaccination time-point, however, would not have been affected by this discrepancy. The post-vaccination time-point analysis of patients based on the different doses of the E75 peptide and GM-CSF certainly could have an impact but did not reveal any significant changes in serum cytokine profiles (data not shown); although, a strong limitation is imposed on this conclusion by the small number of patients in each of these groups. Furthermore, the role and influence of GM-CSF in this study certainly did not escape our concern. All of our NP patients received $250 \mu \mathrm{g}$ of GM-CSF in contradistinction of $125 \mu \mathrm{g}$ of GM-CSF given to most of the NN cohort. If the GM-CSF dosing would affect serum cytokine levels to any significant amount, one would expect that change to become apparent in the NP group due the higher dose of GM-CSF received. This, however, was not our observation. In fact, the NN cohort had the highest levels of all cytokines except eotaxin and IL-13 (neither of which reached statistical significance). The sample size was also relatively small and did not allow adequate statistical analyses of some subset comparison groups.

We are also aware of the difference in the treatment protocols of our NN and NP breast cancer patients. Given that NP patients received chemotherapy significantly more often than their NN counterparts, it would be feasible to question whether such cytokine differences are due to the immunomodulating effects of the cytotoxic agents rather than representative of the tumor-immune system interaction. However, all of our treated patients' serum specimens were obtained at least 14 months following completion of chemotherapeutic regimens and therefore any cytokine pattern modulation detected would be unlikely to represent the direct result of cytotoxic agents at the time of serum donation. However, further studies with pre-treatment patient populations are needed to answer this concern.

In conclusion, we have demonstrated statistically significant differences in the serum cytokine levels of breast cancer patients compared to healthy controls, NP versus NN patients, and in vaccinated patients comparing pre- and post-vaccination serum samples. These differences are intriguing and may hold promise for the further development of serum screening assays potentially useful in diagnosis as well as in staging of breast cancer. Furthermore, cytokine profiles may be useful for the immediate ex vivo monitoring and evaluation of cancer vaccines and clinical trials.

\section{Acknowledgements}

Funded by the Clinical Breast Care Project, a Congressionally funded program of the Henry M. Jackson Foundation for the Advancement of Military Medicine. Supported by the United States Army Medical Research and Materiel Command, and the Department of Clinical Investigation at Walter Reed Army Medical Center.

\section{References}

1. Bast RC Jr, Ravdin P, Hayes DF, Bates S, Fritsche H, Jessup JM, Kemeny N, Locker GY, Mennel RG and Somerfield MR: 2000 update of recommendations for the use of tumor markers in breast and colorectal cancer: clinical practice guidelines of the American Society of Clinical Oncology. J Clin Oncol 19: 1865-1878, 2001.

2. Petricoin EF, Ardekani AM, Hitt BA, Levine PJ, Fusaro VA, Steinberg SM, Mills GB, Simone C, Fishman DA, Kohn EC and Liotta LA: Use of proteomic patterns in serum to identify ovarian cancer. Lancet 359: 572-577, 2002.

3. Alexe G, Alexe S, Liotta LA, Petricoin E, Reiss M and Hammer PL: Ovarian cancer detection by logical analysis of proteomic data. Proteomics 4: 766-783, 2004.

4. Bellisario R, Colinas RJ and Pass KA: Simultaneous measurement of thyroxine and thyrotropin from newborn dried blood-spot specimens using a multiplexed fluorescent microsphere immunoassay. Clin Chem 46: 1422-1424, 2000.

5. Bellisario R, Colinas RJ and Pass KA: Simultaneous measurement of antibodies to three HIV-1 antigens in newborn dried bloodspot specimens using a multiplexed microsphere-based immunoassay. Early Hum Dev 64: 21-25, 2001

6. Carson RT and Vignali DA: Simultaneous quantitation of 15 cytokines using a multiplexed flow cytometric assay. J Immunol Methods 227: 41-52, 1999.

7. Chen J, Iannone MA, Li M-S, Taylor JD, Rivers P, Nelsen AJ, Slentz-Kesler KA, Roses A and Weiner MP: A microspherebased assay for multiplexed single nucleotide polymorphism analysis using single base chain extension. Genome Res 10: 549-557, 2000.

8. Taylor JD, Briley D, Nguyen Q, Long K, Iannone MA, Li M-S, Ye F, Afshari A, Lai E, Wagner M, Chen J and Weiner MP: Flow cytometric platform for high-throughput single nucleotide polymorphism analysis. Biotechniques 30: 661-669, 2001.

9. Peoples GE, Gurney JM, Heuman MT, Woll MM, Ryan GB, Storrer CE, Fisher C, Shriver CD, Ioannides CG and Ponniah S: Clinical trial results of a HER2/neu (E75) vaccine to prevent recurrence in high-risk breast cancer patients. J Clin Oncol 23: 7536-7545, 2005.

10. Hueman MT, Dehqanzada ZA, Novak TE, Gurney JM, Woll MM, Ryan GB, Storrer CE, Fisher C, McLeod DG, Ioannides CG, Ponniah S and Peoples GE: Clinical trial results of a HER2/neu peptide (E75) vaccine for the prevention of PSA recurrence in high-risk prostate cancer patients. Clin Cancer Res 11: 7470-7479, 2005 . 
11. Lee TD: Distribution of HLA antigens in North American Caucasians, North American Blacks and Orientals. In: The HLA System. Lee TD (ed). Springer-Verlag, New York, pp141-178, 1990.

12. Woll MM, Fisher CM, Ryan GB, Gurney JM, Storrer CE, Ioannides CG, Shriver CD, Moul JW, McLeod DG, Ponniah S and Peoples GE: Direct measurement of peptide-specific CD8+ $\mathrm{T}$ cells using HLA-A2:Ig dimer for monitoring the in vivo immune response to a HER2/neu vaccine in breast and prostate cancer patients. J Clin Immunol 24: 449-461, 2004.

13. Halak BK, Maguire HC and Lattime EC: Tumor-induced interleukin-10 inhibits type 1 immune responses directed at a tumor antigen as well as a non-tumor antigen present at the tumor site. Cancer Res 59: 911-917, 1999.

14. Staveley-O'Carroll K, Sotomayor E, Montgomery J, Borrello I, Hwang L, Fein S, Pardoll D and Levitsky H: Induction of antigen-specific $\mathrm{T}$ cell anergy: an early event in the course of tumor progression. Proc Natl Acad Sci USA 95: 1178-1183, 1998.

15. Melchionda F, McKirdy MK, Medeiros F, Fry TJ and Mackall CL: Escape from immune surveillance does not result in tolerance to tumor-associated antigens. J Immunother 27: 329-338, 2004.

16. Lebrecht A, Grimm C, Lantzsch T, Ludwig E, Hefler L, Ulbrich E and Koelbl H: Monocyte chemoattractant protein-1 serum levels in patients with breast cancer. Tumor Biol 25: 14-17, 2004.
17. Hefler L, Tempfer C, Heinze G, Mayerhofer K, Breitenecker G, Leodolter S, Reinthaller A and Kainz C: Monocyte chemoattractant protein-1 serum levels in ovarian cancer patients. Br J Cancer 81: 855-859, 1999.

18. Jose PJ, Griffiths-Johnson DA, Collins PD, Walsh DT, Moqbel R, Totty NF, Truong O, Hsuan JJ and Williams TJ: Eotaxin: a potent eosinophil chemoattractant cytokine detected in a guinea pig model of allergic airways inflammation. J Exp Med 179: 881-887, 1994.

19. Leonard EJ and Yoshimura T: Human monocyte chemoattractant protein-1 (MCP-1). Immunol Today 11: 97-101, 1990.

20. Ogilvie P, Bardi G, Clark-Lewis I, Baggiolini M and Uguccioni M: Eotaxin is a natural antagonist for CCR2 and an agonist for CCR5. Blood 97: 1920-1924, 2001

21. Saji H, Koike M, Yamori T, Saji S, Seiki M, Matsushima K and Toi M: Significant correlation of monocyte chemoattractant protein-1 expression with neovascularization and progression of breast carcinoma. Cancer 92: 1085-1091, 2001.

22. Salcedo R, Ponce ML, Young HA, Wasserman K, Ward JM, Kleinman HK, Oppenheim JJ and Murphy WJ: Human endothelial cells express CCR2 and respond to MCP-1: direct role of $\mathrm{MCP}-1$ in angiogenesis and tumor progression. Blood 96: 34-40, 2000.

23. Gouon-Evans V, Lin EY and Pollard JW: Requirement of macrophages and eosinophils and their cytokines/chemokines for mammary gland development. Breast Cancer Res 4: 155-164, 2002. 